Um die allgemeinen Störungen mit den früher berechneten speciellen zu vergleichen, habe ich folgende zwei Oerter berechnet:

\begin{tabular}{|c|c|c|c|c|c|c|}
\hline Mittl. Berliner Zt. & $n_{0} z$ & ע & $\frac{u}{\cos i}$ & Geoc. AR & Geoc. Decl. & $\log \Delta$ \\
\hline 1865 März 5,5 & $142^{\circ} 21^{\prime} 42^{\prime \prime} 14$ & $+439 " 68$ & $-63^{\prime \prime} 53$ & $164^{\circ} 56^{\prime} 59^{\prime \prime} 57$ & 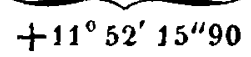 & 0,3234225 \\
\hline 1870 April 2,5 & $18041 \quad 12,56$ & $+226,07$ & $-117,49$ & $19043 \quad 32,47$ & $-45225,65$ & 0,3334178 \\
\hline
\end{tabular}

Für dieselben Zeiten haben die speciellen Störungen gegeben (Berliner Jahrbuch 1867 und 1872):

\begin{tabular}{|c|c|c|c|c|c|}
\hline & & & Geoc: AR & Geoc. Deel. & $\log \Delta$ \\
\hline & März & & $164^{\circ} 57^{\prime} \quad 9^{\prime \prime} 64$ & $+11^{\circ} 52^{\prime} 10^{\prime \prime \prime} 22$ & 0,3234259 \\
\hline & & 2,5 & $19044 \quad 10,68$ & $-45250,09$ & 0,3334277 \\
\hline
\end{tabular}

Die Unterschiede dieser Oerter sind also :

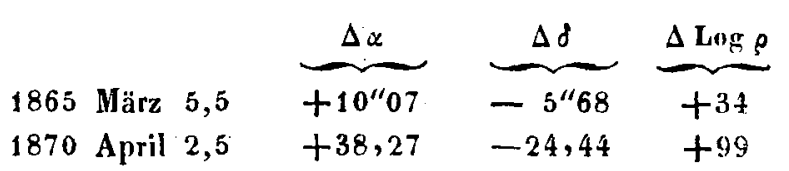

und bieraus findet man folgende Correctionen, die an die oben gegebenen Werthe von $n_{0} z, \nu$ und $\frac{u}{\cos i}$ anzubringen sind, um eine vollständige Uebereinstimmung zwischen den allgemeinen und speciellen Störungen zu erbalten :

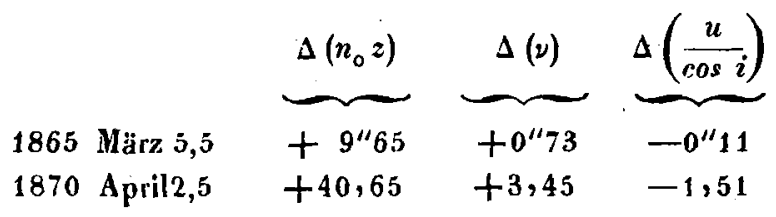

Wenn die beiden Rechnungen richtig geführt sind, müssen diese Zahlen den Einfluss der Störungen höherer Ordnungen angeben.

L u n d, 1870 Januar 31.

\title{
Ueber die Methode der Beobachtung bei Venusdurchgängen.
}

Die Bestimmung der Sonnenparallaxe durch die bei weitem grössere Differenz zwischen der Venus- und Sonnenparallaxe wird um so sicherer sein, wenn diese zu messende Differenz ein Maximum ist; dies ist demnach das richtigste Kriterium für die $W$ ahl der Beobachtungsorte; da aber, wenn man von Grössen zweiter Ordnung absiebt, die Parallaxendifferenz ausschliesslich proportional dem Sinus der Zenithdistanz wächst, so werden alle Orte, bei denen im Verlaufe des Pbänomens die Sonne in einer niederen Stellung wahrgenommen wird, zur Anstellung der Beobachtungen geeignet sein, went man darauf achtet je zwei Orte zu kombiniren, für die sich die parallactische Wirkung summirt; man wird auch nicht die Orte vernachlässigen dürfen, in denen die Wirkung der Parallaxe ein Minimum ist, um neue unabhängige Bedingungen für die Relation der geocentrisehen Rectascensions- und Declinationsdifferenzen zwischen den Centren von der Sonue und Venus zu erhalten.

Mit Rücksicht auf diesen eben entwickelten Gesichtspunkt babe ich begonnen, einen Plan für die Beobachtung des Venusdurchgangs im Jahre 1874 auszuarbeiten, der vielleicht seiner Zeit als Grundlage für eive so wichtige gemeinsame Verständigung dienen könnte, und bin ich dahei auf ein, wie mir scheint, neues Verfabren für die Beobachtung gestossen, welches einige Beachtung verdient. Vor allen möchte ich hervorheben, dass ich schon vor einer Reibe von Jabren im mündlichen Verkehr dic Beobachtung der Contactmomente allein nach dem jetzigen Zustande der Messapparate nicht als gerechtfertigt ansehen möchte und habe hervorgehoben, dass die Anwendung heliometriseher Messungen während des Verlaufes des Phänomens an geeigneten Orten sehr wünschenswerth wäre, ein Umstand, der bereits bei den bisherigen vorbereitenden Arbeiten über den zu erwartenden Venusdurchgang theilweise berücksichtigt wurde. Die Contactmomente ersetzen gleichsam die heliometrische Messung theilweise, indem sie für ein gegebenes Zeitmoment die Distanz der Centren angehen; man wird deshalb sich bei ausschliesslicher Berücksichtigung der Contactmomente auf solche Orte zu beschränken haben, wo der parallaktische Einfluss auf die Distanz ein Maximum wird, eine Beschränkung, die theilweise das Gelingen der Beobachtungen durch Ungunst der Witterung in Frage stellt; nun lässt es sich leicht zeigen, dass der Gürtel der günstigen Beobachtungsorte sofort ein geschlossener wird, wenn man ausser den Contactmomenten auch den Positionswinkel des Eintrittes und Austrittes genau bestimmt; eipe Bestimmung, die nach dem vollkommenen Zustande, in dem die astronomischen Messapparate sich jetzt hefinden, durchaus keiner Schwierigkeit unterliegt; ich will hier nicht eingehen auf die Methoden, die man zu dieser Bestimmung des Positionswinkels anwenden könnte und spare mir die diesbezüglichen Benerkungen für die demnächst zu vollendende ausführliche Bearheitung des Venusdurchganges auf; ich müchte hier nur auch bervorhehen, dass, sobald man diese Messung vollführt bat, die völlig genaue Kenntniss der Länge des Beobaehtungsortes nicht nöthig ist; indem dieselbe nur mehr dazu dient, die geocentrische relative Lage der Mittelpunkte zu bestimmen, also hei der langsamen relativen Bewegung der beiden Centren nur auf wenige Zeitsecunden verbürgt zu sein braucht.

$$
\text { Wien, } 1870 \text { Februar 2. Tl. Oppolzer. }
$$

